\title{
BASE NACIONAL COMUM CURRICULAR: IMPLEMENTAÇÃO DA PROPOSTA CURRICULAR PARA A EDUCAÇÃO INFANTIL NO MUNICÍPIO DE NOVA IGUAÇU
}

\author{
Rejane Peres Neto Costa ${ }^{1}$, Anelise Monteiro do Nascimento ${ }^{2}$, Luana Ramos Neves ${ }^{3}$ \\ ${ }^{1}$ Mestranda em Educação do Programa de Pós-Graduação em Educação, Contextos Contemporâneos e Demandas \\ Populares da Universidade Federal Rural do Rio de Janeiro - UFRRJ. Professora de Educação Infantil no município do \\ Rio de Janeiro e Professora Regente de História na rede estadual do Rio de Janeiro. E-mail: \\ rejaneperescosta@hotmail.com \\ ${ }^{2}$ Doutora em Educação pela Pontifícia Universidade Católica - PUC/Rio com período sanduíche em Université Paris \\ Descartes - Paris V. Professora Adjunta do Departamento de Educação e Sociedade da Universidade Federal Rural do \\ Rio de Janeiro - UFRRJ. E-mail: anelise.ufrrj@yahoo.com.br \\ ${ }^{3}$ Graduanda de Pedagogia pela Universidade Federal Rural do Rio De Janeiro - UFRRJ. Bolsista do Programa de \\ Iniciação Científica do Grupo de Pesquisa Infâncias até os 10 anos - GRUPIs. E-mail: ramosnluana@gmail.com
}

\section{RESUMO}

A pesquisa que apresentamos nesse artigo tem como foco a política instituída pelo Ministério da Educação que propõe a (re)formulação curricular a partir de uma Base Nacional Comum Curricular, Lei 12.796/13. Aqui tratamos especificamente das proposições dessa política para o segmento da Educação Infantil. Acompanhamos nos anos de 2018 e 2019 o trabalho organizado pela Secretaria Municipal de Educação do município de Nova Iguaçu, com o intuito de investigar os desdobramentos de tal política a nível municipal, seus arranjos, ajustes, tensões e resultados. Utilizamos a Análise Relacional de Michael Apple como referencial teórico-metodológico para compreender a formulação de currículos como uma proposta dentro das políticas educacionais. O município estudado cumpriu seu objetivo de reformulação curricular, num cenário de curto espaço de tempo para elaboração do texto, baixa participação da comunidade escolar e ainda sem a publicação/divulgação do documento final.

Palavras-chave: Educação infantil; Base Nacional Comum Curricular; Análise relacional; Política educacional.

\section{CURRICULAR COMMON NATIONAL BASIS: IMPLEMENTATION OF THE CURRICULAR PROPOSAL FOR CHILD EDUCATION IN THE NEW IGUAÇU CITY}

\section{ABSTRACT}

This paper has as object the curriculum (re)formulation policy based on the Brazilian federal law no 12.796/2013 curricular standards, known as Base Nacional Comum Curricular, and implemented by the Brazilian Ministry of Education (Ministério da Educação - MEC). The present article specifically addresses the early childhood education propositions in the mentioned policy. In order to analyze the development of such policy at the municipal level, as well as its arrangements, adjustments, tensions and results, we observed the work developed by the Educational Department of Nova Iguaçu city during the years of 2018 and 2019, department known as Secretaria Municipal de Educação do Município de Nova Iguaçu. As a methodological theoretical framework, Michael Apple's Relational Analysis helped to understand the curricula formulation standards as one proposal among other educational policies. In a short period of time, alongside a school community's low participation scenario and yet without the final document's publication/circulation, the aforementioned city of Nova Iguaçu met its goals of curriculum reformulation. Keywords: early childhood education; common core curriculum; relational analysis; educational policy. 


\section{BASE NACIONAL COMÚN CURRICULAR: APLICACIÓN DE LA PROPUESTA CURRICULAR PARA LA EDUCACIÓN INFANTIL EN CIUDAD DE NOVA IGUAÇU}

\section{RESUMEN}

Este documento presenta un estudio de caso sobre una política instituida por el Ministerio de Educación de (re) formulación Curricular dada por una Base Nacional Curricular Común, aquí abordamos específicamente las propuestas para la Educación de la Primera Infancia. Seguimos el trabajo organizado por la Secretaría Municipal de Educación del Municipio de Nova Iguaçu, para comprender el desarrollo de políticas a nivel municipal, sus ajustes, ajustes, tensiones y resultados. Utilizamos el Análisis Relacional como una herramienta de comprensión para la formulación de planes de estudio y políticas educativas. El municipio estudiado cumplió su objetivo de reformulación curricular, en un escenario de buena participación de la comunidad escolar y la publicación del documento final.

Palabras clave: educación de la primera infância; base curricular nacional común; análisis relacional; política educativa.

\section{INTRODUÇÃO}

Esta pesquisa apresenta o acompanhamento da adequação do currículo proposta pela Base Nacional Comum Curricular (BNCC), Lei 12.796, na etapa da Educação Infantil do município de Nova Iguaçu. A realização de um estudo em um município específico justifica-se pela possibilidade de se investigar uma política pública educacional dentro das suas tensões, expressões e recontextualizações no contexto das práticas. Esta é uma política que está em curso no país e que propõe soluções para os problemas da escola pública a partir da alteração e normatização federal do currículo. Ball (2011) destaca que as políticas podem ser consideradas como algo elaborado para as pessoas, mas a sua efetivação depende da inclusão das pessoas nas políticas. Neste sentido, as políticas colocam problemas para os sujeitos, problemas estes que precisam ser resolvidos nos contextos locais. No caso deste estudo, o contexto local é um município específico, que, assim como os outros 5.570 municípios brasileiros, após a Lei de Diretrizes e Bases (LDB) 9394/96, tornaram-se responsáveis pela oferta da Educação Infantil, primeira etapa da Educação Básica (BRASIL, 1996).

Consideramos urgente e fundamental a análise e discussão de forma crítica desta política, uma vez que a BNCC vai interferir na vida de mais de 50 milhões de estudantes e de 2,2 milhões de professores em mais de 186 mil escolas privadas e públicas da Educação Básica em todo o país (INEP, 2017). Portanto, conhecer os ajustes locais desta política é o objetivo deste artigo.
Para discutir a atual política educacional da BNCC, utilizaremos como referencial teóricometodológico a análise relacional de Michael Apple (1979) como um instrumento de investigação. Em sua vasta produção acadêmica, analisando o papel da educação, Apple situa a educação dentro de um contexto social amplo e a relaciona com as múltiplas facetas da sociedade. O que o autor propõe é a análise das políticas educacionais inseridas no cotidiano das pessoas ao fazerem uso destas políticas num exercício de descrição vívida da realidade social, e relacionando-a com a política, a economia e a cultura numa perspectiva macro. É um exame de como a construção de sujeitos e de conhecimentos cria ajustamentos aos grupos sociais. Nesse caso, propusemos o estudo de como uma política curricular nacional, se concretiza na esfera municipal. Buscamos evidenciar como os sujeitos são afetados e se movimentam para a efetivação da política.

Esta pesquisa atende aos critérios do Conselho de Ética da Universidade à qual pertence. Para desenvolver o tema da recontextualização da política da BNCC no município de Nova Iguaçu, esse texto está organizado em quatro seções, além dessa introdução. Na primeira, apresentamos o referencial teórico-metodológico e o conceito de currículo que operamos em nossas análises; na segunda, trazemos algumas considerações sobre a proposição de uma Base Nacional Comum Curricular como uma política educacional; na terceira, apresentamos dados do campo de investigação, assim como alguns achados da 
pesquisa; por fim, na quarta seção, tecemos algumas considerações finais.

\section{DELINEAMENTO METODOLÓGICO}

Entendemos que uma pesquisa situada no campo da educação compreende uma escolha metodológica que deve levar em consideração os muitos desafios impostos a quem se propõe trabalhar na área das ciências sociais, tal como afirma Minayo (2000), que considera que entrar no campo da Metodologia da Pesquisa Social é penetrar num mundo polêmico no qual há questões não resolvidas, sendo que o debate tem sido perene e não conclusivo.

Optamos por um estudo de campo no qual realizamos entrevistas com os responsáveis pela implementação da política e acompanhamos os encontros e reuniões organizados pela Secretaria Municipal de Educação. Para estudar um evento aparentemente novo como a BNCC, é importante cercar-se de variadas fontes de informação sobre o assunto (análise documental e de literatura, entrevistas e observação direta) para assim realizar uma análise mais ampla dos porquês e desafios da sua implementação. Destacamos a importância da criticidade do pesquisador ao analisar as fontes, a atitude crítica do pesquisador na análise do objeto também constitui a ideia de metodologia de pesquisa. Neste trabalho, o caderno de campo foi utilizado como registro de informações e questões percebidas como potencialmente úteis no campo e que auxiliaram na posterior organização e descrição dos dados obtidos nesta pesquisa. $O$ caderno de campo é um instrumento de pesquisa que possibilita o registro das observações, descrições, ações e conversas, no contexto particular em que os dados são obtidos. É um instrumento utilizado pela etnografia clássica e reconhecidamente provisório, uma vez que, apesar de não integrar a versão definitiva da pesquisa, auxilia o pesquisador a alcançá-la (NASCIMENTO et al., 2018). Uma vez apresentada a escolha metodológica, a seguir trataremos da definição de currículo, categoria central neste trabalho.

A definição de currículo, muitas vezes, é feita da maneira mais comumente disseminada, que faz menção a estrutura dos conteúdos programáticos de uma disciplina ou curso. Para Silva (2010) o conceito de currículo é bem mais amplo, e possui uma especificidade muito particular, pois, todos que dele participam e que têm ingerência sobre ele, não o fazem de maneira neutra. Os valores, ideologias, forças, interesses e necessidades estão impregnados na forma que eles o concebem e exigem. $\mathrm{O}$ objetivo político de quem está no poder em uma determinada sociedade vai influenciar de forma direta nas concepções, nos objetivos e no significado do currículo. Para o autor, ao definir currículo, antes de qualquer coisa, precisa-se responder quatro questões centrais: Para quê ensinar? A quem ensinar? O que ensinar? Como ensinar? (SILVA, 2010).

Nesse mesmo entendimento de currículo, Michael Apple (1979) afirma que as escolas controlam o significado das coisas e decidem qual conhecimento e cultura são legítimos. Dessa forma, utilizaremos as contribuições deste renomado professor, pesquisador e ativista em prol da educação popular e democrática, para o entendimento e categorização de currículo e de políticas educacionais. Apple (1979) propõe uma Análise Relacional do currículo, destacando que ele está atrelado aos modelos históricos-sociais vigentes relativos à economia e à cultura hegemônica que possuem maior força no momento de sua produção. Uma vez transformadas em textos legais, as políticas de currículo, que se fazem de disputas, conversarão com as práticas de um conjunto social ainda maior, impregnando-o de mais tensões e disputas. O currículo não seguirá um curso coeso e único, existirão sim tantas outras demandas locais a serem incorporadas ou rechaçadas.

Para exemplificar o entendimento do uso da análise relacional e sua relevância para o estudo de políticas educacionais, citaremos uma situação narrada pelo próprio Apple em suas investigações.

Apple (2017) narra sua experiência, junto com sua esposa, quando trabalhavam com ativistas, grupos comunitários e com o Ministério da Educação em um dos estados mais progressistas da Índia. Uma iniciativa envolvia a criação de maior acesso a conhecimentos e habilidades técnicas em escolas que atendiam estudantes pobres e marginalizados e, principalmente, mulheres, uma vez que elas estavam marginalizadas duas vezes, não somente pela classe e a casta, mas profundamente pelo gênero e pelas normas patriarcais. Em pouco tempo essa política levou os estudantes para a frente dos computadores. A princípio estava tudo se encaminhando, porém, notaram que só havia meninos frequentando as aulas. A partir daí foi percebida a complexidade da situação, que não 
foi planejada e não foi porque os professores eram machistas. Nessa escola, não havia banheiros limpos para as meninas. Os meninos enfrentavam uma situação semelhante, mas eles poderiam ir atrás do prédio da escola para urinar. Este era um ato com significados e implicações bem diferentes para as meninas. Urinar num lugar público não implicava apenas o risco de ser vista como suja, mas também de ser vista como disponível sexualmente. Por conta disso, para proteger sua reputação, muitas meninas não frequentavam a escola. As meninas que resolveram frequentar a escola, nessas condições, se esforçavam para não beber nada durante o dia, para não precisar urinar. Com o intenso calor e a umidade, muitas meninas ficavam sem energia ou até dormiam sentadas às mesas. Nada disso foi planejado. A política priorizou corretamente um processo escolar que visava a interromper a dominância e estabelecer um currículo e uma coleção de ferramentas que produziriam resultados mais democráticos para estudantes pobres e marginalizados, e isso foi dirigido abertamente à mudança radical da vida de meninas e jovens mulheres. Porém, estudantes têm corpos de gênero. A política de corpos, embutida na materialidade de ambientes físicos, interrompeu a tentativa oficial de cessar a dominação. Coisas simples como banheiros, relações de gênero e a vida cotidiana impossibilitaram essa política (APPLE, 2017).

É nessa perspectiva, da política e dos desdobramentos dela para além das variáveis previstas em seu texto, que este estudo pretende investigar a reformulação curricular de um município de grande porte, buscando adequar-se às normativas da BNCC.

\section{RESULTADO E DISCUSSÃO}

Para definição do objeto de estudo, partimos do pressuposto de que a ideia de adoção de uma base nacional comum para a Educação Básica no Brasil não é recente e tampouco inovadora, sua elaboração está prevista na Constituição Federal (BRASIL, 1988) e na Lei de Diretrizes e Bases da Educação Nacional (BRASIL, 1996). A Constituição prevê no artigo 210 o estabelecimento de um currículo comum: "serão fixados conteúdos mínimos para o ensino fundamental, de maneira a assegurar formação básica comum e respeito aos valores culturais e artísticos nacionais e regionais" (BRASIL, 1988). Na LDB podemos encontrar a seguinte referência

para o tema:

\begin{abstract}
Os currículos do ensino fundamental e médio devem ter uma base nacional comum, a ser complementada, em cada sistema de ensino e estabelecimento escolar, por, por uma parte diversificada, exigida pelas características regionais e locais da sociedade, da cultura, da economia e da clientela (BRASIL, 1996, art. 26).
\end{abstract}

O debate de uma Base Comum Nacional está em pauta constante desde 1997, às vezes mais ou menos robusto, e foi durante o governo de Fernando Henrique Cardoso que o processo de elaboração de um currículo nacional começou efetivamente. A reforma então proposta foi chamada de Parâmetros Curriculares Nacionais (PCNs), e o Conselho Nacional de Educação (CNE) ficou a cargo de criar esses Parâmetros. O documento desenvolvido foi bastante genérico, com orientações curriculares que foram propostas, porém não implementadas pelas autoridades locais, o que possibilitou que estados e municípios conservassem a sua autonomia sobre seus respectivos currículos. Vale citar, ainda nesse período, a elaboração do Referencial Curricular Nacional para a Educação Infantil (BRASIL, 1998) organizado para atender e orientar as especificidades da Educação Infantil. Em 2013 o movimento pela construção de uma base ganha força através da Lei № 12.796/13, que prevê, dentre outras questões, a formulação de uma Base Nacional Comum Curricular (BRASIL, 2013). Finalmente, em 2017, sua elaboração se materializou tomando o lugar de normativa e política pública de âmbito nacional (BRASIL, 2017).

A construção dessa Base teve início em $2010^{1}$, quando especialistas discutiram os direcionamentos da Educação Básica na Conferência Nacional da Educação (CONAE), que visava consolidar um novo Plano Nacional de Educação (PNE). Entre as discussões, destaca-se o início de um debate acerca do dever do Estado de ofertar Políticas Educacionais que possibilitassem iguais condições a todos os sujeitos inseridos na Educação Básica Brasileira. A BNCC se ampara em

\footnotetext{
${ }^{1}$ Disponível em: http://basenacionalcomum.mec.gov.br/historico, acesso em 20/06/2018.
} 
outras políticas educacionais, como as Diretrizes Curriculares Nacionais e o Plano Nacional de Educação (PNE 2014-2024). A Lei no 12.796, em 4 de abril de 2013, alterou a LDB em consonância com a Emenda Constitucional no 59/2009. Esta emenda modificou a idade da escolaridade obrigatória da educação básica para 4 a 17 anos, tornando obrigatória e gratuita a oferta de vagas para esta faixa etária e previu, também, no Artigo 26 uma Base Comum Curricular:

Os currículos da educação infantil, do ensino fundamental e do ensino médio devem ter base nacional comum, a ser complementada, em cada sistema de ensino e em cada estabelecimento escolar, por uma parte diversificada, exigida pelas características regionais e locais da sociedade, da cultura, da economia e dos educandos (BRASIL, 2013).

No ano seguinte à aprovação da Lei $\mathrm{n}$ $12.796 / 13$, os debates em torno da organização de um currículo nacional se intensificaram. A partir daí as discussões tomaram mais corpo, uma vez que a justificativa para sua elaboração foi atrelada ao Plano Nacional de Educação (PNE 2014-2024) no cumprimento das Metas dois e três. Estas metas tratam da universalização do acesso e da conclusão na idade recomendada no ensino fundamental e no médio, questões caras às políticas educacionais brasileiras. Como estratégias para alcançar estas metas, previu-se para a Educação Básica a formulação de uma base nacional curricular garantidora de qualidade na educação, segundo as estratégias do PNE.

De acordo com o Ministério da Educação $\left(M^{2} C^{2}\right)$, a BNCC desde a sua concepção propunha seguir uma dimensão democrática estabelecida na Carta Magna (BRASIL, 1988), organizando sua construção com a participação popular. Porém, deve-se frisar que essa participação se limitou a sugestões de atividades e inclusão de estratégias, não tendo sido possível alterar a sua forma. Essa foi planejada por especialistas em dois eixos: "direitos de aprendizagem e desenvolvimento" e "campos de experiência". Também foram os especialistas que dividiram as crianças da

\footnotetext{
${ }^{2}$ Disponível em: http://basenacionalcomum.mec.gov.br/historico, acesso em 20/06/2018.
}

Educação Infantil em três faixas etárias: bebês (zero a 1 ano e 6 meses), crianças bem pequenas ( 1 ano e 7 meses a 3 anos e 11 meses) e crianças pequenas ( 4 anos a 5 anos e 11 meses). Veremos como esses eixos se desdobram ao longo do texto. Nesse momento queremos ressaltar como a dimensão da participação esteve presente nessa política. Sobre isso, o site do MEC afirma que foram realizados dois encontros com representantes de várias instituições (nós estivemos presentes em algumas etapas da formulação do texto da política): na 2a Conferência Nacional pela Educação (CONAE), entre os dias 19 e 23 de novembro de 2014 e no I Seminário Interinstitucional, entre 17 a 19 de junho de 2015. A consulta pública foi realizada em duas etapas, após a 1a versão da BNCC ser disponibilizada, entre os dias 2 e 15 de dezembro de 2015 e após a 2a versão da BNCC ser disponibilizada, de 23 de junho a 10 de agosto de 2016, quando aconteceram 27 Seminários Estaduais com professores, gestores e especialistas para debater a segunda versão da BNCC. O Conselho Nacional de Secretários de Educação (CONSED) e a União Nacional dos Dirigentes Municipais de Educação (UNDIME) promoveram esses seminários. Em agosto de 2016, começou a ser redigida a terceira versão. Alguns especialistas participaram de todas as versões do documento, outros foram substituídos após a mudança de governo imposta pelo poder legislativo brasileiro em 2016. A versão final da BNCC foi entregue em meados de 2017 e aprovada pelo Conselho Nacional de Educação. Em 20 de dezembro de 2017 a Base Nacional Comum Curricular foi homologada pelo ministro da Educação, Mendonça Filho e em 22 de dezembro de 2017 o CNE apresentou a Resolução CNE/CP no 2, de 22 de dezembro de 2017 que institui e orienta a implantação da Base Nacional Comum Curricular.

É a aproximação com as ideias de Apple (1979) que nos faz questionar esta estrutura de formulação curricular dada a partir de especialistas e com baixa participação de outras instâncias representativas e com pouco diálogo efetivo com os docentes, ou seja, questiona-se a ideia de um currículo nacional nascido fora do campo educacional como aposta para a diminuição das desigualdades regionais. Porém, não há como negar o ressurgimento de uma normativa curricular nacional. A BNCC aglutinou forças políticas distintas em torno de um mesmo objetivo: uma política nacional propositiva de 
currículo, que busca estabelecer o que é apropriado ensinar num território de 8,5 milhões de quilômetros, o quinto maior no mundo, com uma população de 209 milhões de habitantes, quinta maior população mundial, e com uma diversidade cultural imensurável.

O direito à Educação Infantil é bastante claro nos dispositivos legais, já presentes naqueles anteriores à BNCC. Desde a LDB (BRASIL, 1996) há uma produção significativa de documentos publicados para a Educação Infantil pelo MEC: Critérios para um Atendimento em Creches que Respeite os Direitos Fundamentais das Crianças de 1995 e reeditado pelo MEC em 2009 (CAMPOS; ROSEMBERG, 2009), Referencial Curricular Nacionais para a Educação Infantil (BRASIL, 1998), as Diretrizes Nacionais para a Educação Infantil (BRASIL, 2010) - tais documentos orientam as formas de organização em diferentes âmbitos da Educação Infantil. Podemos afirmar, assim, que eles produziram um currículo ao longo deste tempo (KRAMER, 1997). No documento atual há a ratificação e ênfase nessa noção dos direitos das crianças à educação. Sendo a Educação Infantil a primeira etapa da Educação Básica, a proposição curricular também se coloca para ela. Logo, propomos a reflexão do quanto essa política, pensada principalmente para o êxito escolar dado nos conhecimentos comuns aos educandos, fixa aprendizagens, assumindo um contorno de currículo como lista de conteúdos a serem aprendidos, também, pelas crianças pequenas.

O MEC defende que a instituição de uma BNCC não tem como objetivo apresentar um currículo para os municípios. Mas o que nossa pesquisa indica é que, no contexto da prática observada, diante das muitas demandas e do pequeno corpo técnico das secretarias municipais, a BNCC fez emergir um discurso hegemônico de infância, de divisão de conhecimentos ou objetivos sequenciais por faixa-etária. Tal discurso é um resquício da concepção de conhecimento, de sujeito e de currículo focada em conteúdos a serem internalizados ou competências a serem alcançadas. Considerando a especificidade do campo da educação infantil, a BNCC convida, por sua estrutura, a uma sobreposição da concepção de aprendizagem nacional para a local. Nos parece que a base é ainda mais prescritiva no segmento da Educação Infantil do que nos outros níveis de escolarização, como podemos ver nas orientações dadas no campo de experiência "o eu, o outro e o nós", que descreve como as crianças por faixa etária irão interagir umas com as outras e com os adultos, algo impensável para outras etapas da educação escolar (BRASIL, 2017, p. 43). Interagir é um princípio básico da vida, normatizar essa interação é desconsiderar a natureza humana.

Falando desse excesso de prescrições, logo na introdução do texto da BNCC sobre a Educação Infantil são apresentados os eixos estruturantes para a prática pedagógica: as interações e as brincadeiras, tendo como referência para tal entendimento as Diretrizes Nacionais para a Educação Infantil (BRASIL, 2010). A partir destes eixos são estabelecidos seis direitos de aprendizagem para a El: conviver, brincar, participar, explorar, expressar, conhecerse. Como a Educação Infantil se estabelece a partir das interações e das brincadeiras, é proposto no documento que o trabalho seja organizado em cinco campos de experiências a partir dos quais propõe um arranjo curricular com seus objetivos de aprendizagem e desenvolvimento:

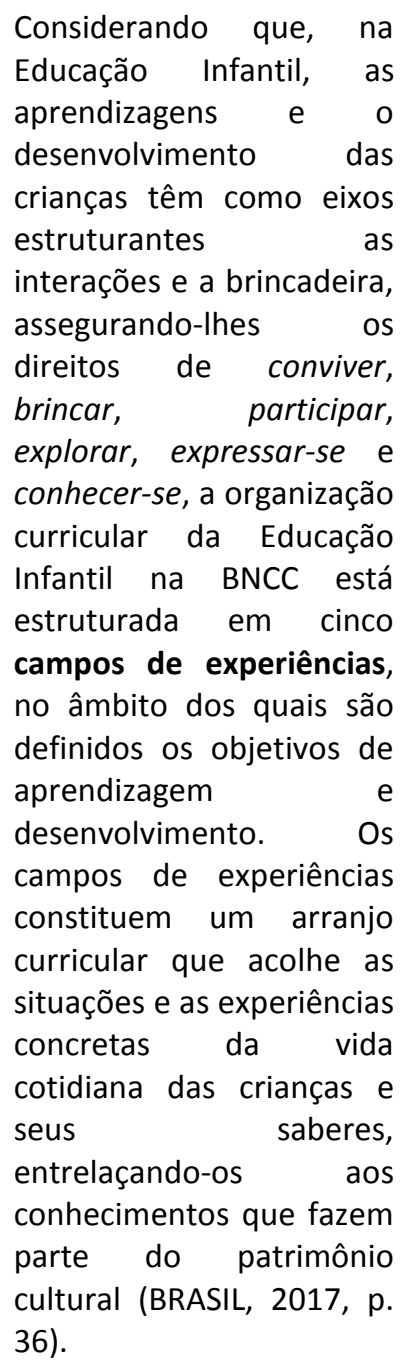


Como já anunciado, consideramos válido pensar sobre como um documento discursivo entrará nas experiências de vida das crianças dentro das instituições de Educação Infantil. Currículo baseado nas experiências é um currículo vivido naquilo que acontece nas escolas, na emergência da vida. Os acontecimentos diários, nos diferentes espaços e, também, na escola, são imprevisíveis e impossíveis de antever. Isso é mais explícito quando tratamos de um segmento da educação que coloca sua centralidade nas experiências dos encontros com os sujeitos - nas interações e nas brincadeiras. O currículo precisa, para tanto, englobar um sentido para além do prescritivo e abrir-se para a capacidade que o encontro de crianças com outras crianças e dos adultos com elas tem de produzir sentidos múltiplos sobre o mundo e não em uma mera repetição de padrões e enunciações sobre o que será vivido.

É necessário levar em conta o diálogo com a expressividade das crianças, o incentivo às suas capacidades de criar cenas, narrativas (com vários suportes), invenção de situações, soluções inusitadas para as questões que emergem do coletivo, permitindo-lhes prosseguir, testar suas hipóteses, experimentar formas novas de relação, sustentar o que constroem (GUIMARÃES, 2012, p. 91).

Esse discurso, que universaliza as instituições de educação, opera com uma imagem negativa da escola, o que é proposto surge para suprir o que nela falta, e naquilo que outros sujeitos consideram importante ou válido, uma vez que aqueles que estão na escola necessitam de tais ajustes, na fala de Apple:

Não é fortuito o conhecimento que se introduziu nas escolas no passado e que hoje se introduz. É selecionado e organizado em torno de conjuntos de princípios e valores que provêm de alguma parte, que representam

determinadas visões de normalidade e desvio, de bom e de mau, e do modo como "agem as boas pessoas". Portanto, se devemos entender por que o conhecimento de apenas alguns grupos foi primeiramente

representado nas escolas, precisamos ver os interesses sociais que em geral orientam a seleção e a organização do currículo (APPLE, 1979, p. 14).

Em trabalho que discute a BNCC, Abramowicz e Tebet (2017) alertam para estas intencionalidades exteriores, explicitadas acima por Apple, naquilo que elas chamam de colonização da pré-escola. Tal intento coloca uma funcionalidade prática e útil para as proposições econômicas desta etapa da educação. A Educação Infantil funcionaria como a solução para os problemas das etapas seguintes da escolarização e, por isso, incumbida de resolver algumas de suas crises, "como o desempenho escolar deficiente e desigual entre as crianças de diferentes classes sociais, gênero e raças. Além disso, essa etapa da educação continua a ser vista como um antídoto contra a pobreza" (ABRAMOWICZ; TEBET, 2017, p. 190).

Nas orientações para a formulação dos currículos municipais, a BNCC prevê a inclusão de objetivos de aprendizagem pautados nas especificidades locais, mas põe um peso maior naquilo que é essencial e obrigatório diante daquilo que será diverso e específico da localidade. Parece que o que se pretende é a homogeneidade. A mobilização por um padrão de aprendizagem, como sendo a possibilidade de se promover a equidade educacional, é apontada por Abramowicz e Tebet (2017), como solução simplista para questões complexas. Na tentativa de unificar pela via da cultura "como se fosse possível culturalizar desigualdades econômicas ou sociais" (ABRAMOWICZ; TEBET, 2017, p. 195).

Descreveremos aqui dois aspectos fundamentais da política da BNCC para a Educação Infantil: os direitos de aprendizagem e os campos de experiência e como eles pretendem orientar as práticas cotidianas das crianças. Como já foi dito, a BNCC para a Educação Infantil está estruturada em campos de experiências, que definem os objetivos de aprendizagem e desenvolvimento. A ideia é relacioná-las aos saberes e conhecimentos 
fundamentais a serem propiciados às crianças e associados às suas vivências. Esses devem configurar a base estrutural pedagógica, ou seja, as propostas curriculares que devem guiar as escolas com as aprendizagens necessárias para cada agrupamento.

Reconhecendo as
especificidades dos
diferentes grupos etários
que constituem a etapa da
$\begin{array}{lr}\text { Educação Infantil, os } \\ \text { objetivos }\end{array}$
$\begin{array}{lr}\text { aprendizagem de } \\ \text { desenvolvimento estão } \\ \text { sequencialmente }\end{array}$

organizados em três grupos por faixa etária, que correspondem, aproximadamente, às possibilidades de aprendizagem e às características do desenvolvimento das crianças (BRASIL, 2017, p. 42).

A estrutura obedece ao seguinte fluxograma:

Quadro I. Fluxograma da BNCC

Educação Infantil

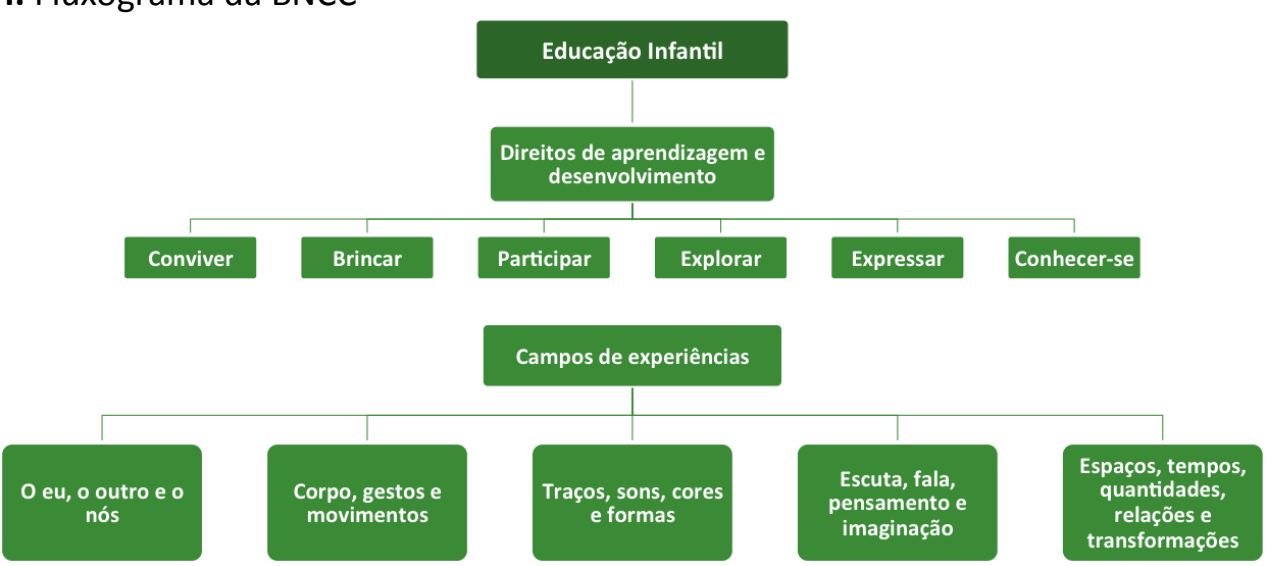

Imagem disponível em: https://www.slideshare.net/GrasielaDourado/bncc-na-prtica, acesso em 23/12/2019.

De acordo com o site do MEC, a definição e a denominação dos campos de experiências também se baseiam no que dispõem as Diretrizes Curriculares Nacionais para a Educação Infantil (DCNEI). A Base traz cinco campos de experiências:

O eu, o outro e o nós: trata da importância da interação das crianças com adultos e seus pares, e como isso influencia na sua construção social. Assim sendo, a Educação Infantil é o espaço no qual se constrói características como autonomia, independência, reciprocidade, senso de autocuidado, que possibilitam aos sujeitos o contato direto com outros grupos sociais, outras culturas e costumes.

Corpo, gestos e movimentos: traz uma preocupação com um repertório de atividades diversificadas, sugere que sejam trabalhados os movimentos corporais e os sentidos com a música, a dança, o teatro e as brincadeiras, permitindo, assim, que a criança ganhe centralidade, explorando o mundo, o espaço e os objetos do seu entorno.

Traços, sons, cores e formas: ao ter contato na escola com diferentes manifestações artísticas, culturais e científicas, as crianças podem ser os sujeitos das suas aprendizagens, sendo agentes de suas próprias criações artísticas e culturais. Portanto, a Educação Infantil precisa promover a participação das crianças em produções como as artes visuais, música, teatro, dança e audiovisual. Tudo a fim de favorecer o desenvolvimento da sensibilidade, da criatividade e da expressão pessoal das crianças.

Escuta, fala, pensamento e imaginação: ouvir a criança na Educação infantil é de extrema importância, é disso que trata este campo. Respeitar o momento de fala e promover os momentos de escuta potencializam a sua participação na cultura oral. Pois é na escuta de histórias, na participação em conversas, nas narrativas e em múltiplas linguagens, que a criança se constitui ativamente como sujeito singular e pertencente a um grupo social. 
Possibilitar uma diversificada e rica variedade de textos, desenhos e possibilidades letradas vão constituir uma relação de apropriação com a escrita.

Espaços, tempos, quantidades, relações e transformações: é importante que as crianças desenvolvam sua curiosidade quanto ao tempo e ao espaço, sendo instigados e esclarecidos nas suas curiosidades. A relação com as coisas e lugares onde estão inseridas as situam no mundo e lhes dão a noção de pertencimento.

Ao lermos os cinco campos de experiências trazidos pela base, podemos observar que conceitos como construção da identidade e construção da autonomia ganham destaque como fundamentais na aprendizagem e formação das crianças. Aqui tratamos da formação de sujeitos: seres expressivos e falantes, produtores e reprodutores de cultura, constituídos por palavras próprias e alheias. Tal especificidade remete atenção e cuidado ao formular um documento normativo que lista competências generalizando-as por grupo etário. Ao voltar o olhar para a Educação Infantil, toda essa concepção de infância que o documento traz em seus campos de experiências se mostra em constante contradição com a ideia das múltiplas infâncias propostas nas Diretrizes Curriculares Nacionais para a Educação Infantil. Se por um lado a BNCC aborda em diversos momentos a importância das múltiplas culturas, por outro, acaba sistematizando a infância (que não é uma, são muitas) em um documento propositor dos currículos de Educação Infantil e que dá a intencionalidade da ação pedagógica. Outro aspecto, repousa nessa intencionalidade prévia do que se vai ensinar na Educação infantil, conteúdos que se revestem de objetivos, alguns deles que já fazem parte da vida das crianças, mesmo daquelas que não têm oportunidade de frequentar a Educação Infantil.

As relações sociais como as escolares são, antes disso, relações humanas, ou seja, relações entre seres humanos concretos, históricos e com identidades pessoais. Cada um que cruza nosso caminho é ao mesmo tempo a alteridade com quem dialogamos sem sínteses, e partilha conosco um tempo e um lugar, suas referências culturais e pertencimento social. Todos os campos de experiências da Base Nacional Comum Curricular trazem em seu texto a importância das trocas de experiências e do outro na construção do conhecimento. É descobrindo o mundo e as pessoas nele existentes que a criança vai se descobrindo, desenvolvendo e se tornando. Nesse sentido, a aprendizagem da criança não é sequencial como propõe a BNCC, ela não espera os três anos para fazer a sonoplastia de uma história, por exemplo. Se ela se encanta pelo mundo de faz de conta, todos os sons que cabem nele, mesmo antes da linguagem oral formalizada, poderão ser executados.

Falar sobre o tema do currículo na Educação Infantil não é algo simples, devido à complexidade do tema. Segundo Barbosa e Oliveira (2016) na visão defendida nas Diretrizes Curriculares Nacionais para a Educação Infantil (BRASIL, 2010), documento anterior à Base já mencionada nesse texto, o currículo está vinculado à vida cotidiana da escola, aos modos de organização das propostas, às interações que se estabelecem entre as crianças, ou entre as crianças e os adultos, à ideia de que as interações, as brincadeiras, as experiências promovem a construção de valores, informações e conhecimentos. O currículo na Educação infantil não pode, portanto, ser algo inflexível e imutável. Ele precisa ser construído pelos sujeitos da Educação Infantil no dia a dia da atividade pedagógica, deve partir deles, de suas realidades e interesses, precisa ser flexível a mudanças de direção a todo momento, respeitando a experiência e a cultura que a criança traz para a escola. O currículo deve ser visto como:

Conjunto de experiências
culturais onde se
articulam saberes da
experiência, da prática,
fruto das vivências das
crianças e conhecimentos
que fazem partem do
patrimônio cultural, na
perspectiva da formação
humana (KRAMER, 2006,
p. 23-24).

Uma vez problematizada a política educacional da BNCC em curso no país, tendo como recorte a Educação Infantil, passaremos agora a descrever como esta política foi recebida e reinterpretada em um contexto local.

A Proposta Curricular do município de Nova Iguaçu datava do ano de 2007, fazendo-se necessário assim sua atualização às diretrizes trazidas pela BNCC, logo, o município já possuía um currículo que era do conhecimento da rede, 
que se estruturava por Projetos.

O grupo de pesquisa no qual as autoras desse artigo se inserem vem realizando o acompanhamento da implementação de outras políticas educacionais no município investigado desde 2010. Para esta pesquisa específica, nosso primeiro contato com a Secretaria Municipal de Educação (SEMED), aconteceu no dia 11 de abril de 2018. Após agendamento prévio, nos reunimos na sede da secretaria junto a Superintendente de Gestão Pedagógica da época. Apresentamos a proposta de trabalho da pesquisa vigente que, dentre outras questões, pretendia acompanhar os trabalhos organizados pelas secretarias de educação dos municípios da Baixada Fluminense ${ }^{3}$, dando visibilidade a: como os sujeitos se ajustam a uma normativa de nível nacional. Neste estudo, o município de Nova Iguaçu foi escolhido para investigação por possuir grande visibilidade e importância na região.

O governo municipal foi eleito para o período de 2017 a 2020, e, na época de desenvolvimento da pesquisa, sua gestão contava com apenas um ano de trabalho. Com esse governo recente foi colocada uma nova equipe na Secretaria de Educação, e, embora o prefeito ainda estivesse em seu primeiro ano de mandato, a Secretaria já contava com seu segundo secretário de educação. Com relação à estruturação da prefeitura, estão subordinados diretamente ao secretário de educação as subsecretarias de Gestão Financeira e Gestão Pedagógica, e, logo a seguir, estão as superintendências e as gerências. Nossa entrevistada ocupa um cargo de médio escalão nessa hierarquia. Como houve mudança de secretário nesse primeiro período da gestão, houveram, por conseguinte, ajustes em toda a equipe, de modo que a superintendente entrevistada havia ocupado recentemente 0 cargo.

Segundo a superintendente, o principal desafio para a Secretaria de Educação estava na formulação de uma nova proposta curricular para o município, desafio maior diante do tamanho da rede e de sua heterogeneidade. Este desafio advinha, de acordo com nossa entrevistada, da necessidade de ajuste à Base Nacional Comum

\footnotetext{
${ }^{3}$ Região geográfica do Estado do Rio de Janeiro que compreende doze municípios integrantes da grande região metropolitana da cidade do Rio de Janeiro: Belford Roxo, Duque de Caxias, Itaguaí, Japeri, Magé, Mesquita, Nilópolis, Nova Iguaçu, Paracambi, Queimados, São João de Meriti, Seropédica.
}

Curricular, construída nos últimos anos e homologada pelo Ministério da Educação (MEC) no ano de 2017. Segundo a superintendente, a gestão atual queria com a política da BNCC cumprir uma dupla tarefa: reformular a proposta local, compondo-a com as novas orientações do MEC e alinhar as diversas unidades da rede. Para tal, a Secretaria distribuiu a equipe técnica em Grupos de Trabalho (GT). O resultado do trabalho desses GTs visava organizar o material, "construído à muitas mãos", segundo as palavras da superintendente, que resultaria na nova proposta curricular da rede. $\mathrm{Na}$ época da entrevista, nos foi informado, que essa publicação ficaria como legado. Segundo a superintendente, esse documento representaria "uma marca do governo" para o Secretário de Educação, já que, com a publicação em DO, tal política atravessaria diferentes mandatos, deixando, assim, um legado do governo que organizou tal normativa (Gerente da El de Nova Iguaçu, Caderno de Campo, 11/04/2018) ${ }^{4}$.

Dentro da perspectiva da Análise Relacional de Michael Apple, a política educacional se relaciona com a dinâmica social e os interesses múltiplos dos sujeitos que a operacionalizam, ou seja, na realidade concreta dos agentes públicos municipais, a construção de um currículo pode representar um ganho político de maior durabilidade (GANDIN; LIMA, 2016).

O trabalho de campo, a partir desse primeiro encontro, foi percorrer as estratégias organizadas pela rede municipal para sua reformulação curricular. Isto se deu por meio do acompanhamento da agenda da SEMED, e principalmente do GT de Educação Infantil. A Secretaria tinha a pretensão de consultar as 134 escolas de Ensino Fundamental e 21 Escolas Municipais de Educação Infantil, a partir de atividades na própria unidade e, também, por encontros nos quais estivessem presentes representantes das diversas escolas.

O marco desta consulta ocorreu com o "Dia D da BNCC", dia 6 de março de 2018. Esta data foi sugerida pelo MEC para ser organizadas reuniões pelas secretarias e escolas como o dia de apresentações, debates e compartilhamentos sobre a BNCC junto às equipes técnicas, equipes gestoras, professores, pais e alunos. As escolas do município de Nova Iguaçu também foram

\footnotetext{
${ }^{4} \mathrm{O}$ caderno de campo foi utilizado como instrumento de registro da pesquisa, conforme explicitado neste trabalho.
} 
chamadas a conhecer a BNCC. Neste dia houve, seguindo as orientações e estímulo da SEMED, encontros organizados pelas equipes gestoras com a comunidade escolar, realizados nas diferentes unidades escolares. A partir daí a SEMED colocou em prática os grupos de trabalho (GTs), coordenados pelos membros da Secretaria, para discutir a nova BNCC e a reformulação do currículo do município com os profissionais vindos de diferentes escolas. Estes grupos foram formados pelas diferentes gerências, a saber: a Educação Infantil, a Educação de Jovens e Adultos, o primeiro segmento do Ensino Fundamental, o segundo segmento do Ensino Fundamental e a Educação do Campo. Para a superintendente, ali se apresentava outro nó para a gestão desse momento: o reduzido quadro de profissionais diante do enorme volume de trabalho, haja vista que o prazo para conclusão desta proposta era setembro de 2018, em sua fala "os grupos são diminutos e possuem uma enorme incumbência, a formulação e a execução das atividades" (Gerente da El de Nova Iguaçu, Caderno de Campo, 11/04/2018).

O primeiro encontro dos GTs para a elaboração da proposta curricular da rede aconteceu no Campus de Nova Iguaçu da Universidade do Norte do Paraná (UNOPAR) no dia 28 de maio de 2018. Estiveram presentes todos os representantes das diferentes Gerências de Educação da SEMED, alguns professores que compunham os GTs, muitos diretores de escolas e alguns representantes de unidades escolares da rede particular ${ }^{5}$. Nesse primeiro momento aconteceu um seminário geral sobre a BNCC divulgado pela Superintendente de Educação Infantil, ela fez uma breve apresentação do material do Ministério da Educação, expondo a Base Nacional Comum Curricular e falando de sua importância para a reorganização da proposta curricular do município. Logo em seguida, os presentes se dividiram em grupos, segundo seus respectivos GTs e iniciaram as discussões específicas de cada grupamento (Caderno de Campo, 28/05/2018).

O GT de Educação Infantil, nosso objeto de observação, participou de outros dois encontros, em cada um deles havia um número diferente de pessoas. Somente no primeiro encontro esteve presente uma representante de

\footnotetext{
${ }^{5}$ Não tivemos acesso ao quantitativo de pessoas da rede privada, nem de quais instituições eram.
}

uma escola privada. O segundo e o terceiro encontro aconteceram nos dias 11 e 18 de junho na Escola Municipal Doutor Thibau. Estavam presentes nestes dois encontros a Gerente da Educação Infantil, uma professora de sua equipe e a diretora da EM Dr. Thibau, porém, as professoras que constituíam o GT de Educação Infantil não foram as mesmas nos dois encontros. No primeiro encontro o grupo realizou a leitura da proposta curricular de 2007 e a seguir iniciou a conversa apontando e sugerindo mudanças ou permanências possíveis, tendo como suporte a organização curricular estruturada nos cinco Campos de Experiências propostos pela BNCC. O grupo se subdividiu em três, conforme organizado pela Base, o grupo que trataria de bebês, outro grupo de crianças bem pequenas e por fim o grupo de crianças pequenas. Houve um pequeno debate nesses subgrupos sobre as proposições da Base e daquilo que já tinham na proposta curricular do município. Por ser um trabalho extenso e que demandava mais tempo, ficou acertado que em um próximo encontro todos trariam suas contribuições e assim poderiam apresentar uma proposta para a revisão curricular (Caderno de Campo, 11/06/2018).

No terceiro e último encontro, o grupo de professores dispôs de um tempo reduzido, apenas duas horas, para fazer seus apontamentos, alterar o que acreditavam ser necessário da antiga proposta e atualizá-la segundo as novas proposições da BNCC. O grupo tentou fazer uma análise das múltiplas concepções de infâncias presentes no munícipio, mas a falta de tempo não permitiu a continuidade da discussão. Pareceu-nos que a reformulação da proposta pedagógica anterior, a priori, partiria de um princípio reflexivo a partir da BNCC, mas se tornou, na realidade, uma junção da antiga proposta com o que propunham os campos de aprendizagem da BNCC. Elencaram atividades já realizadas por elas no seu fazer cotidiano e presentes no documento antigo do município e que poderiam estar nos campos de experiências. Diante do material colocado à disposição e do entendimento de currículo dado nos dispositivos legais apresentados, o grupo realizou os ajustes (Caderno de Campo, 18/06/2018).

A SEMED realizou mais um encontro, no dia 7 de novembro de 2018, dessa vez, das 
Gerências de Educação com os coordenadores pedagógicos de todas as escolas, para apresentação do que havia sido produzido até ali pelos diferentes GTs. Neste encontro, a Subsecretária de Educação esteve presente. Apesar do convite aos coordenadores ser para uma discussão sobre a proposta curricular, o que houve, de fato, foi a fala da subsecretária de educação ressaltando a importância da confecção do documento, os esforços que o governo estava fazendo para tanto, inclusive priorizando tal ação e finalmente a apresentação pelas gerentes de educação dos esboços do que fora construído até ali. Os ajustes finais seriam realizados nas escolas, com a promoção de reconhecimento do documento preliminar. As unidades receberiam o que fora elaborado até ali pelos grupos de trabalho, e cada escola poderia fazer até duas sugestões, sendo acréscimos ao documento e não intervenções ao que já estava pronto, como salientado. Todas as ações deveriam ser registradas em Ata e sendo obrigatória a presença na reunião do Conselho Escolar. A presença do conselho foi colocada como essencial por ser um documento preliminar e exigir uma consulta pública, garantida a partir deste encontro nas escolas com toda comunidade escolar, formada por alunos (Fundamental II) e responsáveis dos alunos. As sugestões deveriam ser encaminhadas logo após a discussão realizada na escola, e os apontamentos organizados, de forma que 0 documento fosse finalizado e pudesse ser publicado, o que ocorreu no dia 26 de fevereiro de 2019. Estas etapas, o chamamento da comunidade escolar, composta por docentes, discentes e responsáveis é que permitiu aos representantes da Secretaria de Educação chamar tal processo de democrático e construído conjuntamente por toda a comunidade escolar (Caderno de Campo, 7/11/2018).

Em uma etapa posterior da pesquisa, realizamos outra entrevista, no dia 02 de junho de 2019, com a então Gerente de Educação Infantil, que havia assumido recentemente seu cargo. Vale ressaltar que ela integrava a equipe que participou da elaboração da nova proposta curricular do município em outra função. Isso demonstra a troca dos cargos e a descontinuidade com a identidade do trabalho por elas iniciado. Durante a conversa a gerente relatou como a agenda para elaboração da
Proposta Curricular foi complicada, levando em conta os diferentes contextos que as escolas estão inseridas em toda a cidade e os atravessamentos políticos que se fizeram presentes. A entrevistada destacou a descontinuidade dos trabalhos anteriores na secretaria, não só no que se refere à adequação do currículo à BNCC, mas a todos os projetos planejados, que sofrem impactos pelas trocas constantes dos cargos. Por fim, lamentou a nova Proposta Curricular, que apesar de publicada em Diário Oficial, ainda não havia se materializado como instrumento de trabalho nas escolas (Gerente da El de Nova Iguaçu, Caderno de Campo, 2/06/2019).

\section{CONCLUSÕES}

Durante esta pesquisa a Secretaria de Educação passou por trocas constantes de secretários e num efeito cascata foram, também, trocados os gestores na secretaria, num cenário que pouco favoreceu o andamento de uma política que previa a reelaboração curricular com a participação democrática. $\mathrm{O}$ número reduzido de participantes no Grupo de Trabalho da Educação Infantil, a escassez de material para debate e os poucos encontros promovidos, assim como a falta de sequência de uma reunião para a outra com pessoas diferentes em cada reunião, foram entraves para a redação do texto final. A dinâmica adotada pelo município pouco colaborou para um debate mais profundo e que contribuísse para a confecção de um material mais polissêmico. $O$ resultado se aproxima mais de uma lista de atividades a serem executadas por grupamentos nas diferentes escolas, do que uma proposta que reconheça os diferentes contextos presentes no município de Nova Iguaçu, que parecem não caber nos Campos de Experiências propostos pela BNCC.

Embora a Proposta do Currículo do município tenha sido homologada em fevereiro de 2019, sua entrada nas escolas não foi imediata. Não foi nem ao menos divulgado o material final, visto que, no Diário Oficial, sua publicação somente cita a existência de uma nova Proposta Curricular, mas não traz o novo documento. Sua divulgação ainda não havia acontecido até a escrita deste texto, o que impossibilitou que esta pesquisa avançasse na análise do seu material, deixando, assim, algumas 
questões para pesquisas futuras. Durante a primeira entrevista com a gerente de educação, uma fala chamou a atenção e se tornou muito reveladora para este trabalho, ao ser questionada se acreditava que a construção da nova Proposta Curricular havia acontecido de forma democrática, a entrevistada respondeu "acredito que o documento foi democrático dentro da realidade da rede" (Caderno de Campo, 11/04/2019). Em um primeiro momento a ideia de uma participação democrática com limitações causa estranhamento, mas olhando tanto a produção do texto na esfera nacional, como no contexto local, o que os propositores da política estão entendendo como participação democrática se aproxima mais de uma validação do que de uma construção coletiva.

A fala inicial, durante o primeiro encontro, de uma nova proposta curricular construída coletivamente com toda a rede, se mostrava bastante interessante e rica, porém, não se concretizou (Caderno de Campo, 11/04/2019). Com poucos encontros, pouco tempo de discussão, escassez de material propositivo para reflexões, o que ocorreram foram encontros com objetivos a serem alcançados num curto espaço de tempo. "O tempo não é nosso aliado", como mais tarde a gerente de educação falou na reunião com os coordenadores pedagógicos, no último encontro antes da promulgação da Resolução (Caderno de Campo, 7/11/2018). De uma oportunidade para os professores trazerem para a política suas vivências, como na primeira reunião, em que assuntos como inclusão, diversidade cultural, preconceito, letramento e participação dos responsáveis foram abordados, os encontros seguintes, movidos pela urgência em terminar o documento, os quais tornaram impossível que esses assuntos voltassem a ser falados e que houvessem discussões sobre os diferentes contextos da rede, tornando o processo maçante e mecanizado.

Contudo, podemos afirmar que 0 conjunto proposto pela BNCC parece ter penetrado no documento municipal, uma vez que os maiores esforços foram para promover entendimento e adequação ao modelo proposto pelo MEC. E, por fim, um objetivo central dos gestores do município foi alcançado, o documento foi elaborado seguindo bem próximo os prazos estabelecidos e pôde se tornar uma normativa legal publicada em Diário Oficial e, assim, deixar a "marca" de um governo em uma política que se projeta de longa duração para a cidade.

Podemos enfim enunciar algumas outras questões, além das já apresentadas ao longo do texto, que apontam para a necessidade de investigação desta política: quais impactos esse novo currículo terá na vida das crianças? Que impacto terá na aprendizagem e no desenvolvimento das crianças? Sabemos que há um crescente número de livros didáticos, inclusive para a Educação Infantil, que surgiram no mercado editorial apontando soluções para a implementação dessas políticas nos contextos locais; que papel terá o livro didático neste novo contexto? Essas são questões que esta pesquisa não se propôs e nem foi capaz de responder, porém essa reflexão se faz de extrema importância.

Com relação à análise de uma política curricular proposta por atores externos, o que percebemos por parte dos gestores de Nova Iguaçu foi o sentimento de cumprimento de uma tarefa dada por uma entidade maior, sem se relacionar profundamente com os interesses dos sujeitos que efetivamente vão viver esta política no cotidiano.

\section{AGRADECIMENTOS}

Os autores declaram não haver potencial conflito de interesses que possa interferir na imparcialidade deste trabalho científico. Agradecem à CAPES e à FAPERJ pelos financiamentos recebidos.

\section{REFERÊNCIAS}

ABRAMOWICZ, A.; TEBET, G. G. C. Educação infantil: um balanço a partir do campo das diferenças. Pro-Posições, v. 28, p. 182-203, 2017. https://doi.org/10.1590/1980-6248-2016-0114

APPLE, M. W. Ideologia e currículo. São Paulo, SP: Editora Brasiliense, 1979.

APPLE, M. W. A luta pela democracia na educação crítica. São Paulo: Revista eCurriculum, v. 15, n. 4, p. 894-926, 2017. 10.23925/1809-3876.2017v15i4p894-926. 
BALL, S.; MAINARDES, J. (Org). Políticas educacionais: questões e dilemas. São Paulo: Cortez, 2011.

BRASIL. Constituição da República Federativa do Brasil. Brasília, DF: Senado, 1988. Disponível em: http://www.planalto.gov.br/ccivil 03/constituica o/constituicao.htm. Acesso em: 09 ago. 2019.

BRASIL. Lei no 9.394, de 20 de dezembro de 1996. Lei de Diretrizes e Bases da Educação Nacional. Brasília, DF: Presidência da República, 1996. Disponível em: http://www.planalto.gov.br/ccivil 03/Leis/L9394. htm. Acesso em: 09 ago. 2019.

BRASIL. Ministério da Educação e do Desporto, Secretaria de Educação Fundamental. Referencial curricular nacional para a educação infantil. Brasília: MEC/SEF, 1998. Disponível em: http://portal.mec.gov.br/seb/arquivos/pdf/volu me3.pdf. Acesso em: 09 ago. 2019.

BRASIL. Secretaria de Educação Básica. Diretrizes curriculares nacionais para a educação infantil. Brasília, DF: MEC, 2010. Disponível em: http://portal.mec.gov.br/index.php?option=com docman\&view=download\&alias=9769diretrizesc urriculares-2012\&category slug=janeiro-2012pdf\&Itemid=30192. Acesso em: 09 ago. 2019

BRASIL. Lei no 12.796, de 4 de abril de 2013. Altera a Lei $\mathrm{n}^{\circ} \mathbf{9} .394 / 1996$, dispondo sobre obrigatoriedade da matrícula a partir dos 4 (quatro) anos de idade. Brasília, DF: Presidência da República, 2013. Disponível em: http://www.planalto.gov.br/ccivil 03/ ato20112014/2013/lei/l12796.htm. Acesso em 09/08/2019.

BRASIL. Lei no 13.005, de 25 de junho de 2014. Plano Nacional de Educação (PNE). PNE 20142024. Brasília: Câmara dos Deputados, 2014. Disponível em: http://portal.inep.gov.br/documents/186968/48 5745/Plano+Nacional+de+Educação+PNE+20142024++Linha+de+Base/c2dd0faa-7227-40eea520-12c6fc77700f?version=1.1. Acesso em 09/08/2019.

BRASIL. MEC. Base nacional comum curricular: BNCC, 2016-2017. Brasília: MEC, 2017.
BRASIL. Movimento pela base comum. Brasília: BNCC, 2018. Disponível em: http://movimentopelabase.org.br. Acesso em: 02 fev. 2019

BRASIL. Ministério da Educação. Histórico da base nacional comum curricular. Disponível em: http://basenacionalcomum.mec.gov.br/historico. Acesso em: 02 jun. 2019.

BARBOSA, M. C. S.; OLIVEIRA, Z. R. Currículo e linguagem na educação infantil. 1.ed. Brasília: MEC/SEB, 2016. Disponível em: http://www.projetoleituraescrita. Acesso em: 12 abr. 2019.

CAMPOS, M. M.; ROSEMBERG, F. Critérios para um atendimento em creches que respeite os direitos fundamentais das crianças. 2.ed. Brasília: MEC, SEB, 2009. Disponível em: http://portal.mec.gov.br/dmdocuments/direitosf undamentais.pdf. Acesso em: 02 jun. 2019.

GANDIN, L. A.; LIMA, I. G. A Perspectiva de Michael Apple para os estudos das políticas educacionais. Educação e Pesquisa, São Paulo, v. 42, n. 3, p. 651-664, 2016. https://doi.org/10.1590/S1517$\underline{9702201609143447}$

GUIMARÃES, D. Educação Infantil: espaços e experiências. In: CORSINO, Patrícia (org.). Educação infantil: cotidiano e políticas. Campinas, SP: Autores Associados, 2009. p. 1532.

KRAMER, S. Propostas pedagógicas ou curriculares: subsídios para uma leitura crítica. Educação \& Sociedade, Campinas, v. 18 , n. 60 , $1997 . \quad$ https://doi.org/10.1590/s0101$\underline{73301997000300002}$

KRAMER, S. Com a pré-escola nas mãos. São Paulo: Ática, 2006.

MINAYO, M. C. S. O desafio do conhecimento: pesquisa qualitativa em saúde. São Paulo: Hucitec, 2000.

NASCIMENTO, A. M.; BARBOSA, S. N. F.; MATTOS, M. N. S. Infância, experiência e etnografia na 
educação infantil. Revista Contemporânea de

Educação, v. 13, n. 26, 2018.

https://doi.org/10.20500/rce.v13i26.14357

SILVA, T. T. Documentos de identidade: uma introdução às teorias do currículo. Belo Horizonte: Autêntica, 2010. 